- RAM, REV. ADM. MACKENZIE, 15(3), Edição Especial • SÃO PAULO, SP • MAIO-JUN. 2014 • ISSN 1518-6776 (impresso) • ISSN 1678-6971 (on-line) • http://dx.doi.org/10.1590/1678-69712014/administracao.v15n3p69-100. Submissão: 7 out. 2013. Aceitação: 9 maio 2014.

\title{
1 ATRIBUTOS DA TRANSAÇÃO E \\ MENSURAÇÃO, E SUA INFLUÊNCIA \\ NAS RELAÇÕES ENTRE COOPERADOS \\ E COOPERATIVAS EM SISTEMAS \\ AGROINDUSTRIAIS SUINÍCOLAS
}

\section{DANIELE DE LOURDES CURTO DA COSTA MARTINS}

Mestra em Administração pelo Departamento de Administração da Universidade Estadual de Maringá (UEM).

Professora do Departamento de Administração do Centro Universitário Leonardo Da Vinci (Uniasselvi). BR 470, 1.040, Km 71, Benedito, Indaial - SC - Brasil - CEP 89130-000

E-mail: danielecurto@yahoo.com.br

\section{JOSÉ PAULO DE SOUZA}

Doutor em Engenharia de Produção pelo Departamento de Engenharia de Produção da Universidade Federal de Santa Catarina (UFSC).

Professor associado do Departamento de Administração da Universidade Estadual de Maringá (UEM). Avenida Colombo, 5.790, Jardim Universitário, Maringá - PR - Brasil - CEP 870520-900

E-mail: jpsouza@uem.br 


\section{RESUMO}

Neste artigo, busca-se discutir as relações entre os cooperados e as cooperativas especificamente em transações suinícolas, as quais envolvem atributos da transação e dimensões mensuráveis. Para tanto, o objetivo deste artigo foi compreender como os atributos da transação e a mensuração podem influenciar nas relações contratuais entre produtores e processadores em estruturas cooperadas suinícolas localizadas na região oeste do Paraná. Teoricamente, recebeu suporte das teorias dos custos de transação de Williamson (I985) e dos custos de mensuração de Barzel (2005). Para atender ao objetivo proposto, realizou-se uma pesquisa qualitativa de cunho descritivo em duas cooperativas no oeste paranaense. A coleta de dados foi desenvolvida por meio de obtenção de dados secundários da Organização Brasileira de Cooperativas, de institutos de pesquisa, da Secretaria da Agricultura e de órgãos relacionados à atividade de suínos. Os dados primários foram obtidos por meio de uma entrevista semiestruturada com as cooperativas e os produtores. Como resultado, identificou-se que a estrutura de governança utilizada pelas cooperativas se caracteriza como híbrida, a qual, mesmo na presença de alta especificidade de ativos, se justifica pela possibilidade de mensuração. Os contratos entre as partes são formais e informais. Em relação ao contrato formal, este tem relevância para as partes no sentido de trazer garantia e continuidade da atividade. Entretanto, a presença de aspectos acordados envolvendo certa especificidade e mensuração pode gerar perda de direito de propriedade, notadamente para os produtores. Identificou-se também que os contratos passam a desempenhar um duplo papel na relação entre as partes: I. geram o equilíbrio na relação e reduzem a possibilidade de comportamento oportunista, em razão do investimento especifico realizado e da necessidade de obtenção de

70 padrão de produto e processo; 2. são utilizados como um mecanismo para manter o cooperado produtor de suíno como sócio fiel na cooperativa, atuando como uma forma de manutenção na relação agente e principal. 


\section{PALAVRAS-CHAVE}

Custos de transação. Custos de mensuração. Contratos. Cooperativas. Cadeia suinícola.

\section{INTRODUÇÃO}

As estruturas de mercado têm se alterado muito ao longo do tempo, pois as empresas buscam se manter competitivas em um cenário de maior concorrência, alinhando inovações tecnológicas com redução de custos. As cooperativas, dentro desse contexto, vêm ganhando papel de destaque na economia do país, uma vez que participam ativamente em vários segmentos, como consumo, crédito, produção, agropecuário, entre outros. Nesta investigação, considerando a estrutura cooperada, o foco principal será a cadeia suinícola. Assim, faz-se necessário destacar que os agentes estudados (cooperativas e cooperados) estão envolvidos com a produção, comercialização ou processamento de suínos. Assim, no estudo busca-se compreender a estrutura de governança, sob a consideração dos atributos de transação e mensuração, que permeiam as relações entre cooperados e cooperativas.

Entende-se por atributos da transação a frequência, a incerteza e especificidade dos ativos em uma determinada transação (Williamson, I985). Quanto à mensuração, entende-se o controle ou a obtenção de informação completa e confiável que se tem sob determinada transação, decomposta em dimensões mensuráveis, passíveis de medição ou monitoramento (Barzel I997, 2005).

Nota-se que a prática do cooperativismo vem de longa data. Com o advento do capitalismo, muitas empresas surgiram no mercado e alguns trabalhadores foram explorados. Nesse sentido, alguns pensadores começaram a questionar as práticas das empresas e o que eles consideravam como injustiças sociais (Bialoskorski, I998a). Nesse ambiente, o cooperativismo teve seu desenvolvimento de forma mais intensa a partir do século XIX. As doutrinas do cooperativismo foram criadas seguindo o pensamento de um sistema econômico igualitário e justo. Sob influência dessas ideias, um grupo de trabalhadores que buscavam melhores condições de trabalho fundou a primeira cooperativa. Assim, o cooperativismo tem seu marco a partir da experiência de cooperação em Rochdale, na Inglaterra, em I844, com a cooperativa de consumo.

No final desse século, a organização cooperativa se consolidou e teve apoio de organizações como a Aliança Internacional Cooperativa (ACI) que atualmente 
se faz presente em cinco continentes (Bialoskorski, 2007). O objetivo do sistema cooperativista é, para Zylbersztajn (I994), atender aos produtores, oferecendo-lhes suporte técnico, preços melhores, apoio em infraestrutura e participação na divisão dos lucros.

No Brasil, o movimento cooperativista emergiu no final do século XIX, em Ouro Preto, em Minas Gerais, com uma cooperativa de consumo, expandindo depois para outros Estados. Mas, somente em I995, o cooperativismo brasileiro foi reconhecido internacionalmente. As cooperativas constituem um segmento economicamente forte no país e até o ano de 20 I2 somaram um total de 6.587 cooperativas, com I0,4 milhões de associados distribuídos em I3 ramos de atuação. Dessas I.528 são cooperativas agropecuárias, e hoje 50\% dos produtos agropecuários passam por uma cooperativa, assim distribuídos: I5,I\% para os Estados Unidos, I3,2\% para a China, 6,5\% para os mercados árabes e 6,4\% para a Alemanha, conforme dados do Instituto Brasileiro de Geografia e Estatística - IBGE (Organização das Cooperativas Brasileiras, 20I3).

Nos Estados do Sul, as cooperativas também se desenvolveram principalmente em comunidades de origem alemã e italiana que conheciam as práticas do cooperativismo. Em 20I2, o cooperativismo brasileiro exportou US $\$ 6$ bilhões em produtos, sendo $98 \%$ dessa pauta oriunda da agropecuária. O Paraná concentra US\$ I,7 bilhão, ou seja, 29,2\% da comercialização externa do país, perdendo apenas para o Estado de São Paulo, responsável por US\$ 2 bilhões $(33,9 \%)$ dos produtos comercializados externamente pelo Brasil (Organização das Cooperativas Brasileiras, 20I3). No Paraná, até 20I2, 240 cooperativas agrupavam mais de 735 mil cooperados, e, dentre essas cooperativas, 8I eram cooperativas agropecuárias (Organização das Cooperativas do Estado do Paraná, 20I3). Ainda segundo os dados da Organização das Cooperativas do Estado do Paraná (2013), as cooperativas de agronegócio são responsáveis por 55\% da economia agrícola do Estado.

Quando se considera o sistema suinícola, observa-se que o seu desempenho no Estado do Paraná, a sua estrutura organizacional e a participação das cooperativas na produção justificam o direcionamento do estudo para o Estado. No Brasil, foram abatidas, em 20II, 36.975.725 cabeças, sendo o Paraná responsável por I9,I\% ou 7.054.00I cabeças (Secretaria de Estado da Agricultura e do Abastecimento, 2013). De acordo com os dados do Anuário da Pecuária Brasileira (20II), é possível verificar, no Estado, crescimento no efetivo de suínos, que passou de 4.258.075 cabeças em 200I para 4.913.724 em 20II. Na região oeste, o efetivo de suínos passou de I.I72.386 cabeças em 2000 para I.995.965 em 2009, o que corresponde a quase $40 \%$ do total do Estado do Paraná, o que justifica o direcionamento empírico da pesquisa para essa região. 
Diante do exposto, na presente investigação, busca-se entender os relacionamentos entre as cooperativas e os produtores de suínos, quando o último é cooperado. Nessa orientação, torna-se significativo compreender o aumento da complexidade dos relacionamentos entre cooperado e cooperativa, devido à ampliação das especificidades e dimensões mensuráveis na transação tanto nas relações contratuais formais como em acordos de cooperação. Nesse contexto, o presente artigo tem como objetivo compreender como os atributos da transação e a mensuração podem influenciar as relações contratuais, envolvendo agentes produtores e processadores, em estruturas cooperadas suinícolas, localizadas na região oeste do Paraná.

Para tanto, além desta introdução, o presente artigo está assim estruturado: na seção 2, apresenta-se a revisão da literatura que discorre sobre os estudos sobre custos de transação e custos de mensuração, e a teoria da agência; a seção 3 trata dos procedimentos metodológicos utilizados na pesquisa, os quais envolveram pressupostos qualitativos e análise de dados primários, por intermédio do método de análise de conteúdo; na seção 4, constam a apresentação e análise dos resultados; e, na seção 5, fazem-se as considerações finais.

\section{REVISÃO DA LITERATURA}

A Nova Economia Institucional (NEI) surge questionando a teoria neoclássica. Enquanto esta trata a firma como fator de produção, aquela considera que o mecanismo de preço não é suficiente para explicar as ações dos agentes no mercado (Coase I937; Zylbersztajn, I995; Farina, Azevedo, \& Saes, I997).

Em se tratando diretamente da NEI, um dos marcos para o seu surgimento foi o trabalho de Coase (I937), segundo o qual, quando se considera que o mercado funciona apenas pelo mecanismo de preço e que a firma é um fator de produção, pouco é possível fazer para que as organizações possam ter melhorias em seus processos e se diferenciar no mercado. Nesse sentido, Coase (I937) argumenta que a firma existe para que as relações no mercado possam ocorrer e que, em muitos casos, a integração vertical acaba sendo mais viável do que o mercado em relação, quando se consideram os custos associados.

Para regulamentar as ações das firmas, as instituições passam a desempenhar um papel importante no mercado. Nas palavras de Farina et al. (I997, p. 30), sua função é "regulamentar e impor as regras ao jogo econômico. Essas regras, por sua vez, fazem parte do conjunto de instituições que formam um determinado ambiente institucional". O ambiente institucional é visto como a base para o desenvolvimento das organizações, uma vez que é seu papel delinear 
os caminhos em que as organizações poderão se desenvolver. North (I99I) e Williamson (2000) tratam as instituições como regras vistas a partir da perspectiva econômica e de manutenção do mercado. Para Williamson (2000), instituições importam e são, também, suscetíveis a análises a partir das ferramentas da teoria econômica.

\subsection{ECONOMIA DOS CUSTOS DE TRANSAÇÃO}

A economia dos custos de transação (ECT) tem como marco inicial os trabalhos de Coase (I937), em seu artigo "The nature of the firm", em que o autor discute o funcionamento dos mercados e os custos associados à movimentação dos agentes. Williamson (I985) esclarece que a NEI tem preocupação com a firma não somente como função produção, mas também como estruturas de governança e que a ECT faz parte da pesquisa tradicional da NEI.

O foco da ECT, de acordo com Williamson (1985), está centrado nas firmas, nos mercados e nas relações contratuais, estando no limite entre mercado e hierarquia, o que vai ao encontro da proposta do presente estudo, uma vez que o objetivo é estudar a firma como cooperativa e as relações contratuais entre estas e os produtores, tendo como objetivo principal de estudo a transação. Na ECT, consideram-se dois pressupostos comportamentais: a racionalidade limitada e o oportunismo, fundamentais para a compreensão da teoria.

Williamson (I993) sustenta que a racionalidade limitada resulta da condição de competência cognitiva limitada de receber, recuperar e processar as informações, já que, devido a essa característica, os contratos, por sua natureza, são incompletos. Em relação ao oportunismo, Williamson (1985) esclarece que trata-se do autointeresse do indivíduo, o que inclui algo mais aparente, mas não é limitado a isso, como enganar, mentir e roubar. Assim, o autor considera que o oportunismo, para a ECT, é estabelecido por meio do uso incompleto ou distorcido da informação e, de alguma forma, associado ao fato de enganar, disfarçar ou confundir.

Quanto aos atributos da transação, existem três diferentes características na ECT: frequência, incerteza e especificidade dos ativos. Essas características e os pressupostos comportamentais configuram as estruturas de governança adotadas pelas firmas (Williamson, I985).

Em relação à frequência, Williamson (1985) explica que, quando a transação é recorrente, o custo gerado por ela é mais fácil de ser recuperado. A incerteza, por sua vez, refere-se às mudanças no ambiente econômico e impossibilita avaliações precisas sobre determinadas ações. Quanto maior for a incerteza, mais complexo será o desenvolvimento de parcerias de longo prazo e maior a 
possibilidade de desentendimentos quando existe possibilidade de recontratação (Saes, 2009).

Quanto à especificidade dos ativos, Williamson (1996) salienta que é o grau que um ativo pode ser utilizado para outros fins, sem perda de seu valor ou de utilização. Nesse caso, quanto mais específico for um ativo, mais a firma tenderá a integrar verticalmente devido à maior dificuldade de controle. Ocorre uma dependência bilateral entre os agentes, o que implica estruturas mais adequadas. Nesse tipo de dependência, uma transação via mercado onera os custos das empresas. De acordo com Williamson (I996), as especificidades podem ser as seguintes: humana, locacional, de ativo dedicado, de ativo físico, de marca e temporal. Quando se relacionam os pressupostos comportamentais e os atributos presentes na transação, configuram-se as estruturas de governança, os quais são tratados por Williamson (I985) como mercado, integração vertical ou uma forma híbrida - envolvendo a relação contratual.

A transação via mercado ocorre quando o principal fator é o preço, já que a especificidade do ativo também é baixa, e, por isso, o produto pode ser encontrado e transacionado via mercado. Ao contrário, a integração vertical se torna mais vantajosa quando os ativos são mais específicos e quando existe maior necessidade de controle sobre as atividades. Williamson (1985) delineia que essa estrutura de governança se caracteriza por internalizar as atividades dentro da empresa devido à alta especificidade dos ativos.

Para entender quando uma firma está integrada, deve-se olhar para a distribuição de suas capacidades (Jacobides \& Winter, 2005). Um dos motivos listados por Jacobides e Winter (2005), que pode levar as empresas a integrar verticalmente, é a dificuldade da capacidade de reposta dos atuais fornecedores em desenvolver novos produtos ou melhorar os produtos já fabricados. Isso leva a empresa a englobar as transações (Azevedo, 2000) que o fornecedor ou distribuidor desenvolvia. Cabe destacar que, segundo Zylbersztajn (2005b), nem sempre ser o maior é melhor, pois o que se busca é a redução de custos e eficiência, e isso deve estar alinhado às decisões da empresa.

Para Zylbersztajn (I999 como citado em Sexton, I986), as vantagens para a integração cooperativa provêm de uma possível relação da redução dos custos e do gerenciamento dos custos irrecuperáveis devido à perecibilidade do produto, com a vantagem de contrabalancear o poder de mercado. Isso significa que, para a organização cooperativa, internalizar as atividades e deixar o produtor atrelado a contratos pode ser um aspecto-chave para o gerenciamento e desenvolvimento da cooperativa, ou seja, pode, devido a esses motivos, diferenciar-se das empresas de capital que concorrem com ela no mercado. Dessa forma, entende-se que a integração das cooperativas possa ser justificada, ainda, pela busca do controle dos ativos transacionados. 
A terceira estrutura de governança tratada por Williamson (I985) refere-se às formas híbridas ou contratuais, as quais, segundo o autor, podem ter características tanto formais quanto informais, mas sempre baseadas na confiança e reputação entre as partes. A contratação também traz custos para as empresas, e essa estrutura exige salvaguardas contratuais, pois existe a possibilidade de não cumprimento dos contratos (Zylbersztajn, 2009).

Ménard (2004) oferece um complemento à proposta de Williamson para melhor compreensão das formas híbridas, o qual pode variar entre o mercado e a hierarquia. Para o autor, as formas híbridas envolvem os acordos multilaterais e bilaterais, com ênfase na primeira, já que estes revelam melhor as características-chave das formas híbridas. Quando se considera a relação contratual como estrutura de governança, a teoria dos custos de transação assume que o agente pode agir de modo oportunista, caso os contratos fiquem expostos a ações que necessitam de monitoramento e salvaguardas contratuais (Zylbersztajn, I995). Isso, por sua vez, incide em custos de transação devido à necessidade de controle sobre a ação dos agentes para que seja possível o enforcement, ou seja, fazer valer os contratos firmados. Logo, quanto mais específicos são os ativos, maiores são as chances de apropriação da quase renda, ficando o modo contratual mais custoso se comparado com a integração vertical.

Verifica-se, dessa forma, que, na ECT, para a decisão acerca do alinhamento entre estruturas de governança e atributos da transação, é considerado o trade-off entre incentivo e controle. Quando a empresa busca o mercado, geralmente este apresenta os incentivos às ações desejadas. Quando a estrutura passa a ser integrada, ocorre a troca do incentivo pelo controle (Farina et al., I997).

É valido ressaltar, na presente discussão, as considerações de Zylbersztajn (I995) que considera que os contratos têm custos associados ao seu funcionamento. O autor explana que esses custos se referem ao desenho, à implementação e ao monitoramento, além dos custos para solucionar disputas que podem surgir devido ao descumprimento das relações contratuais estabelecidas e as características dos agentes, sendo o oportunismo e racionalidade limitados. Um aspecto importante é a incompletude contratual que se relaciona com a impossibilidade de prever todas as contingências futuras por causa da racionalidade limitada e do oportunismo dos agentes envolvidos em uma determinada transação. No mesmo sentido, Hart e Holmström (I987) e Hart (I995) explanam que estudar detalhadamente o processo de contratação e entender seus riscos e imperfeições é importante para fazer uma análise mais plausível das questões econômicas, relacionadas tanto aos contratos formais quanto informais. Nesse sentido, os autores argumentam que os contratos servem para os mercados de competição imperfeita, pois existem diferenças nas transações entre os agentes. 


\subsection{ECONOMIA DOS CUSTOS DE MENSURAÇÃO}

Outra vertente tratada sob a perspectiva da NEI é a economia dos custos de mensuração (ECM). Para Zylbersztajn (2005a), a perspectiva da ECM é mais geral do que a ECT, uma vez que abrange, além da coordenação vertical, a coordenação horizontal e a estrutura interna das organizações. Nesse caso, entende-se que a ECT tem como foco principal as especificidades dos ativos, e, na ECM, de acordo com Barzel (2005) e Zylbersztajn (2005a), a unidade de análise são as dimensões mensuráveis garantidas por direitos de propriedade e pelo uso da informação pelos agentes.

Nesse caso, quanto mais informações forem obtidas em relação à determinada transação, menores serão as possibilidades de haver problemas futuros em uma contratação. Porém, Barzel (2005) adverte que é preciso verificar como essa informação chega até os agentes que estão envolvidos em determinada transação e buscá-la em fontes confiáveis e de qualidade. Isso significa que uma das partes pode ter informações privilegiadas ou que a informação disponível seja incompleta, o que gera dificuldades de mensuração e onera os custos de monitoramento. Para explicar o uso da informação como centro da teoria, Barzel (2005) insere o direito de propriedade. Para Barzel (I997), direito de propriedade consiste no direito que um indivíduo tem sobre determinado ativo ou o poder para consumi-lo, obter resultado dele ou aliená-lo. Nesse caso, o direito econômico sobre determinado bem sugere que é daquele agente que detém esse direito e que pode fazer uso desse ativo de forma direta ou indireta por meio da troca (Barzel, 2005).

O autor observa que o direito das pessoas sobre determinado ativo nunca é constante, mas é função de seu esforço direto na proteção, de outras pessoas e do governo e que pode ser alterado pelas próprias ações individuais. Isso significa que, quanto mais problemas de definição de direito de propriedade, mais os indivíduos usarão recursos para garantir esse direito. Dessa forma, considera-se que os direitos estão inicialmente em domínio público e podem ser mais bem definidos quando é possível determinar quem será o último proprietário (Barzel, I997).

Barzel (2003, p. 5I, tradução nossa) diferencia direito de propriedade a partir de duas perspectivas ${ }^{\mathrm{I}}$ : a primeira refere-se ao "direito econômico que reflete na habilidade, em termos de expectativa para com um produto ou serviço. O direito econômico para um ativo é geralmente menos do que o valor presente nesses bens e serviços produzidos por meio de um ativo"; já a segunda trata o direito legal como aquele "que reconhece que um determinado ativo é de propriedade de um 
indivíduo particular ou de um conjunto de indivíduos. O direito econômico é garantido por empresas privadas, e o direito legal, pelo Estado".

O fato é que, para a ECM, existem custos porque os direitos de propriedade não são bem definidos (Barzel, I997). E, devido a isso, se torna difícil para a empresa proteger esse direito, o que pode levá-la a buscar a integração vertical pela dificuldade de mensuração dos atributos transacionados. Desse modo, para Zylbersztajn (2005a), a ECM busca, por meio das dimensões mensuráveis, uma justificativa para a integração vertical. Nesse caso, quando existe a possibilidade de mensuração ou se é fácil de fazer, a empresa pode optar pelo contrato. Caso não seja, então a empresa pode fazer a atividade de forma interna. Os custos de mensuração se associam, portanto, à captura de valor, e, se é necessária a mensuração para proteger esse valor, o oportunismo é visto na teoria de forma implícita (Barzel, 2005; Zylbersztajn, 2005a).

Entende-se que, entre ativos diferentes, existem variações quanto aos seus atributos, o que impede que seja realizada uma mensuração exata de cada um. Assim, as dificuldades para obter informação completa definem, também, a dificuldade de delinear os diretos de propriedade (Barzel 2003). Nesse caso, existem custos associados à diferença do que cada agente busca alcançar na transação, o que resulta nos problemas entre o agente e o principal. Desse modo, o principal tem dificuldade em conseguir que o agente trabalhe para alcançar seus objetivos. Barzel (2003) sugere que os contratos têm a função de direcionar as trocas de direito de propriedade entre os indivíduos, minimizando os custos e maximizando o valor gerado.

\subsection{TEORIA DA AGÊNCIA}

Complementa esse arcabouço teórico a abordagem da teoria da agência, a qual Williamson (I985) classificou como integrante da vertente que enfatiza os incentivos e envolve ainda direitos de propriedade. Além disso, Hart e Holmström (I987) observam que a abordagem deve ser considerada em consonância com a teoria dos contratos. Nesse caso, uma relação bilateral envolvendo um agente e outro, considerado principal, é abordada. O principal é visto como aquele que tem o poder de decisão sobre a ação, e o agente é o responsável por implementar e receber o incentivo que cubra os custos dessa ação (Hart \& Holmström, I987).

Nas palavras de Milgrom e Roberts (I992, p. 2I4, tradução nossa), "o problema geral de motivar uma pessoa ou organização para que possa agir em nome de outro é conhecido entre os economistas como o problema do agente e do principal". Para os autores, esse problema não ocorre somente devido ao tipo de incentivo pago, mas também por questões relacionadas ao trabalho, ao desenho 
das instituições para reunir as informações, à proteção dos investimentos, à distribuição da decisão e à garantia dos direitos de propriedade. Bialoskorski (I998b) avalia que, da relação contratual existente entre o agente e o principal, bem como dos problemas de agência decorrentes dessa relação, podem surgir custos contratuais que são formados, principalmente, por três questões. A primeira diz respeito ao monitoramento do agente por parte do principal, para que aquele atue de acordo com seus interesses. A segunda questão surge por causa do esforço da manutenção das relações contratuais entre eles. E a terceira refere-se aos custos decorrentes da perda residual causada pela redução do bem-estar do principal, em razão das divergências de interesses ocasionadas ao longo da relação.

Esses custos ocorrem, de acordo com o autor, porque a elaboração do contrato é feita ex ante, ou seja, em um momento que antecede a ação. Assim, como os contratos são incompletos, poderá ocorrer o oportunismo contratual se houver assimetria de informação e alterações de comportamento dos agentes. O autor ressalta ainda que tanto o estabelecimento como a manutenção de contratos geram o que é chamado de moral hazard ${ }^{2}$ e adverse selection ${ }^{3}$, que, por sua vez, causam direitos residuais e de controle.

Vistos dessa forma, os problemas de agência se relacionam com o problema de incentivo, que são causados pela assimetria de informação, já que as relações entre eles podem ocorrer por meio de contratos implícitos ou explícitos como forma de minimizar os custos de agência (Hart \& Holmström, I987). Assim, um dos lados detém certas informações às quais a outra parte, por algum motivo, não tem acesso. Isso pode ocorrer, pois uma das partes pode ter conhecimento privilegiado sobre suas capacidades e ter a oportunidade de verificar algo que não está disponível a outra parte (Adam, 200I). Assim, o principal deve induzir o agente, oferecendo-lhe incentivo para fazer o que é necessário e para agir conforme o interesse do principal e, também, dar a chance ao agente de atender aos seus próprios interesses.

A teoria da agência, portanto, debruça-se sobre o problema do conflito de interesse entre o principal e o agente, e quando as ações executadas por este são difíceis de ser observadas por aquele (Liberatore \& Luo, 20I0). Liberatore e Luo (20I0) observam que o pano de fundo na teoria da agência é constituído por

2 O moral hazard ou risco moral acontece quando os indivíduos se envolvem em uma partilha e existe o compartilhamento do risco, em que as ações tomadas podem afetar a distribuição da probabilidade do resultado. A fonte do moral hazard ou o problema de incentivo consiste na assimetria de informação entre os indivíduos, pois as ações individuais não podem ser observadas por completo (Holmström, I979).

3 A seleção adversa é decorrente do pagamento de incentivo devido ao uso de informações pré-contratuais. Milgrom e Roberts (I992) afirmam que a seleção adversa é um problema de oportunismo pré-contratual devido a um agente ter informação privilegiada antes da contratação. 
dois pontos principais: as assimetrias de informação e a incompatibilidade de objetivos. No primeiro caso, sugere-se que o principal saiba muito menos sobre as reais capacidades e as ações dos agentes. No segundo, quando existe essa incompatibilidade, o agente pode tentar alcançar mais seu próprio benefício, aproveitando-se das assimetrias de informação e agindo de forma oportunista.

Ainda, em uma análise econômica do sistema cooperativo, Bialoskorski (200I) esclarece que a relação do cooperado cumpre um papel triplo na cooperativa de associado; cliente e proprietário, ao mesmo tempo, podem ocasionar o problema, tratado por esse autor e também por Zylbersztajn (I994, I999), da separação entre propriedade e controle. Isso faz com que sejam gerados custos de transação e custos de agenciamento. Nesse sentido, Zylbersztajn (I999) complementam que o duplo papel do cooperado o induz a estruturar a atividade produtiva como um capitalista, ao mesmo tempo que participa de uma sociedade que é gerida pelos princípios da cooperação.

Para Demsetz (1983), a separação entre propriedade e controle é típica de organizações modernas e recentemente passou a ser estudada sob a perspectiva da teoria econômica da firma ${ }^{4}$. Assim, essa separação ocorre quando passam a existir divergências de interesse entre o proprietário e o gerente, em que os controles realizados anteriormente não são desenvolvidos como antes da divergência. Nesse caso, passam a ser criados novos controles e surgem novos interesses e novos relacionamentos.

De acordo com Alchian e Demsetz (I972), devido ao relacionamento entre os atores em uma organização, existe a necessidade de monitorar os esforços das pessoas, o que gera também a hierarquia dentro das organizações. Como esse monitoramento traz custos, isso é feito somente até o ponto em que os benefícios se igualam aos custos de monitoramento do shirk5. Mas quem monitora o monitor? Essa é uma pergunta, no mínimo, intrigante. A solução dos autores seria o residual claimant ${ }^{6}$, no sentido de o monitor ter seu salário baseado no esforço geral da equipe. Nesse caso, aquele agente que não desenvolve suas atividades de forma correta, ou seja, não atende ao que lhe foi estabelecido, pode prejudicar o trabalho de outro agente. O agente que, de alguma forma, age

Demsetz (1983) tem como base os trabalhos de Berle e Means (I932) para essa definição.

5 Para Alchian e Demsetz (I972), o shirk pode ser entendido quando o funcionário não desempenha suas tarefas da forma correta ("corpo mole") e se faz necessário monitorar seu desempenho para reduzir essa prática. Isso significa que shirk é uma espécie de fuga de suas obrigações reais no trabalho que está sendo desempenhado; em vez de buscar atender aos objetivos do principal, ele passa a visar aos próprios objetivos. Além disso, o shirk é discutido pelos autores quando o trabalho ocorre em equipe, pois, pelo volume de trabalho total da equipe, fica difícil mensurar o trabalho individual.

6 Residual claimanté o reclamante residual, que recebe pelo esforço de seu trabalho, além de ter o direito sobre o excesso do resíduo e de exercer o controle sobre o que está sendo realizado (Alchian \& Demsetz, I972). 
de forma oportunista pode tentar levar vantagem sobre o agente que trabalha de forma correta, se o trabalho - ou a tarefa - feito por eles for medido pelo desempenho global da equipe, levando ao chamado freerider ${ }^{7}$.

Uma das formas de minimizar os custos de agência é tratada por Shapiro (2005), o qual sustenta que algumas formas de incentivos, monitoramento e de controle social ajudam a minimizar esses custos de agência. Para Holmström (I979), os recursos utilizados para desenvolver ações de monitoramento eficazes devem constituir também os elementos do contrato. O autor complementa que um desses elementos pode ser uma melhor forma de fazer constar em contrato e, em caso do não cumprimento, ter sanções para penalizar o comportamento do agente. Isso significa que o contrato passa a ser um subsídio para forçar um comportamento adequado, além de ser uma ferramenta para punir uma ação negativa.

\section{PROCEDIMENTOS METODOLÓGICOS}

O presente artigo tem como objetivo compreender como os atributos de transação e mensuração influenciam as relações entre produtores e processadores em estruturas cooperadas suinícolas localizadas na região oeste do Estado do Paraná, conforme as categorias de análise apresentadas na Figura I.

\section{FigURA I}

\section{REPRESENTAÇÃO DAS CATEGORIAS ESTUDADAS}

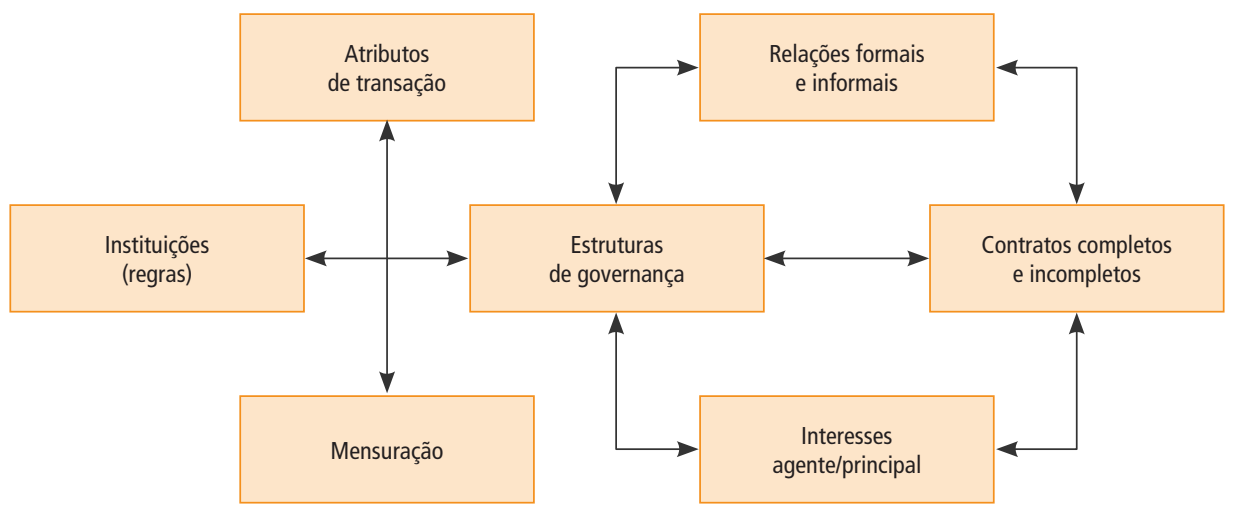

Fonte: Elaborada pelos autores.

Segundo Klein, Crawford e Alchian (1978), freerider é o efeito carona de que determinado agente faz uso para obter benefício devido à ação de outro agente. 
Com base na figura apresentada, busca-se compreender como as instituições desempenham seu importante papel no regramento e influenciam, devido a isso, todas as categorias estudadas. A base principal está centrada na formação da estruturas de governança, que é determinada a partir dos atributos da transação e mensuração, cuja presença pode indicar a estrutura de governança mais adequada. Além disso, a estrutura de governança, por meio de contratos, busca o alinhamento desses atributos de transação e mensuração, com o objetivo de reduzir os custos e alinhar os interesses do agente e do principal, o que retorna para a estrutura de governança. Porém, esses contratos são influenciados também pelas relações formais e informais, por meio da natureza dos contratos incompletos, pois, devido a margens não contratadas, ocorrem relações informais entre os cooperados e cooperativas que passam a influenciar tanto a atividade suinícola como a relação dentro da estrutura cooperada.

O método considerado adequado para que se possa atender a esse objetivo foi a pesquisa qualitativa, pois busca compreender como são influenciadas as relações entre cooperativas e cooperados, quando são considerados os atributos de transação e mensuração, pois esta pesquisa desenvolve-se de modo descritivo. Creswell (2007) explica que a pesquisa qualitativa é fundamentalmente interpretativa, o que significa que o pesquisador interpreta os dados coletados. $\mathrm{Na}$ presente investigação, foram desenvolvidas ainda a pesquisa documental e a pesquisa de campo. Conforme explicam Ludke e André (I986), a pesquisa documental engloba materiais escritos que podem ser usados como fonte de informação, como leis, normas, cartas, jornais, revistas, entre outros. Os principais documentos que serão analisados são os contratos das cooperativas com os produtores, para que seja possível identificar os benefícios e os problemas dos contratos estabelecidos entre as partes.

A pesquisa de campo, conforme Merriam (I998), é caracterizada pela compreensão de um fenômeno, um processo, ou pelas perspectivas e pela visão global do processo envolvido. Geralmente, os dados são coletados por meio de entrevistas, observações ou análises de documentos, sendo uma mistura de descrição e análise, porém, segundo essa autora, não chega a ter a profundidade de um estudo de caso.

Os dados primários foram obtidos por meio de entrevista semiestruturada com os gerentes das cooperativas e com dez produtores de cada cooperativa. Após a realização das entrevistas, elas foram transcritas para posterior interpretação e discussão dos resultados. Nesse tipo de procedimento, o pesquisador deve ter abertura para buscar informações que, muitas vezes, não seriam possíveis por intermédio de uma entrevista fechada, tendo em vista a importância da percepção do cooperado em relação à cooperativa. 
Os dados secundários foram buscados em várias entidades, como Organização das Cooperativas do Estado do Paraná (Ocepar), Organização das Cooperativas Brasileiras (OCB), Instituto Paranaense de Desenvolvimento (Ipardes), Secretaria de Estado da Agricultura e do Abastecimento (Seab), IBGE, Associação Brasileira da Indústria Produtora e Exportadora de Carne Suína (Abipecs) e Empresa Brasileira de Pesquisa Agropecuária (Embrapa), com o objetivo de entender e caracterizar tanto as cooperativas no Paraná como a cadeia suinícola.

Das 82 cooperativas de agronegócio existentes em todo o Estado do Paraná, I6 estão localizadas no oeste do Estado do Paraná, local escolhido para o desenvolvimento da pesquisa por oferecer a maior concentração de cooperativas de proteína animal. Dessas I6 cooperativas, seis estão envolvidas com comercialização ou abate ou processamento de suínos. Das seis uma trabalha diretamente com as outras cinco cooperativas no que se refere à produção de suínos e não atende ao critério de relações contratuais com produtores.

Dentre as cinco, foram inicialmente selecionadas três cooperativas para o estudo. Porém, uma cooperativa não concordou com o estudo, e, por isso, desenvolveram-se as pesquisas em duas cooperativas, denominadas "A" e "B", em razão da representatividade no setor e da acessibilidade. No processo de escolha, adotaram-se os seguintes critérios: a cooperativa deveria estar envolvida com a comercialização ou abate ou processamento de suínos, estar há mais de I5 anos no mercado e apresentar relação contratual com o cooperado. Os critérios para seleção se justificam pelo objetivo do estudo.

Entrevistaram-se 20 produtores in loco, dez produtores de cada cooperativa, com o objetivo de verificar se havia especificidades relacionadas ao tempo de contratação e de integração na organização cooperada, a fim de obter a convergência dos dados coletados. A seleção das cooperativas e dos cooperados foi feita por julgamento, de modo a atender aos critérios estabelecidos para a pesquisa.

Assim, as entrevistas foram gravadas e, posteriormente, transcritas. A transcrição foi efetuada e arquivada em formato Excel, para permitir o acesso para a discussão e análise dos resultados. A análise de conteúdo, que seguiu as determinações de Bauer e Gaskell (2002), foi utilizada para compreender os resultados das entrevistas semiestruturadas, tanto com os gerentes das cooperativas como com os produtores que mantêm contratos formais ou informais com as cooperativas analisadas. Esta análise parte das categorias que foram estruturadas em conformidade com o objetivo da pesquisa e relacionadas com as teorias estudadas. 


\section{APRESENTAÇÃO E ANÁlise DOS RESULTADOS}

Para atingir o objetivo geral proposto neste trabalho, a seção está organizada como segue. Primeiramente, faz-se a apresentação dos dados, tendo como pontos principais o perfil dos produtores de suínos e uma breve caracterização das cooperativas; analisam-se a dinâmica da produção e o papel das instituições; fazem-se as análises em relação aos atributos de transação e mensuração presentes nas transações que envolvem a cadeia de suínos; por fim, apresentam-se as relações entre o produtor como agente e a cooperativa como principal.

\subsection{CARACTERIZAÇÃO DAS COOPERATIVAS E DOS PRODUTORES DE SUÍNOS}

A cooperativa "A" atua no mercado desde I964, com recepção, armazenagem e comercialização de grãos, e localiza-se no oeste no Estado do Paraná. A partir da década de I980, passou a atuar com industrialização de alguns produtos e entrou também no ramo de supermercados. Conta com I3 unidades agrícolas e ainda desenvolve atividades de avicultura e suinocultura. De acordo com o gestor, a cooperativa conta hoje com uma unidade de produção de sêmen e três unidades de produção de leitões (UPLs), e são produzidos aproximadamente I3 mil leitões em cada uma, além da produção de mais I.700 leitões com nove produtores iniciadores. Os suinocultores terminadores somam I88 vinculados à cooperativa. Em 20II, a cooperativa abateu 3I4 mil cabeças que representaram $7 \%$ do total de suas atividades.

A cooperativa "B", que também se localiza na região oeste do Paraná, iniciou as atividades em I963, com a comercialização de grãos: feijão, arroz, milho e café; atualmente destacam-se as culturas de soja, milho e trigo. Além das atividades de grãos, a cooperativa atua na avicultura, piscicultura e suinocultura. A cooperativa conta com dez unidades, um complexo industrial de frangos e uma fábrica de rações na região oeste do Paraná, e também atua no ramo de supermercados. No caso da suinocultura, em 20 II foram abatidas cerca de 200 mil cabeças, o que representou cerca de $6 \%$ das atividades da cooperativa. Para a produção de leitão, a cooperativa "B" conta com três UPLs com capacidade total de I4 mil leitões e mais três produtores iniciadores com capacidade de cerca de dois mil leitões por mês e IIo produtores terminadores para a produção de suínos.

Quanto aos produtores, a Tabela I resume os dados coletados, identificando os principais pontos que traçam seu perfil e também as principais características da atividade suinícola. Um aspecto a ser destacado é que, dentre os produtores 
entrevistados, o tamanho médio da propriedade é de iı,7 ha. Esse dado ratifica o que diz a Ocepar, pois, segundo a organização, os produtores paranaenses cooperados são, em geral, pequenos e médios com propriedade de até 50 ha.

TABELA I

PERFIL DOS PRODUTORES ENTREVISTADOS

\begin{tabular}{lcccc}
\hline & $\begin{array}{c}\text { MAIOR VALOR } \\
\text { ENCONTRADO }\end{array}$ & $\begin{array}{c}\text { MENOR VALOR } \\
\text { ENCONTRADO }\end{array}$ & MÉDIA \\
\hline Tamanho da propriedade (ha) & 26,9 & 2 & 11,7 \\
\hline Tempo em que é cooperado (anos) & 38 & 5 & 18,7 \\
\hline Porcentagem da renda dos suínos do total & $90 \%$ & $20 \%$ & $51 \%$ \\
\hline Tempo na atividade de suínos (anos) & 36 & 5 & 12,3 \\
\hline Tempo de contrato com a cooperativa (anos) & 20 & 3 & 8,8 \\
\hline Capacidade total (terminação) & 1.000 & 200 & 638,5 \\
\hline Pessoas envolvidas na atividade & 4 & 1 & 2,6 \\
\hline Quantidade de barracões & 2 & 1,5 \\
\hline
\end{tabular}

Fonte: Elaborada pelos autores.

Dentre os entrevistados, alguns produtores têm vínculo com a cooperativa há mais de 30 anos, e o tempo médio encontrado entre eles foi de i8,7 anos. Quando questionados sobre a diversificação das atividades, todos os produtores afirmaram que desenvolvem outras atividades, sendo as principais culturas a de milho e soja. E, nesse caso, a renda dos suínos é um complemento à plantação de grãos. Além dos grãos, três produtores tinham também aviários, e nove, pecuária leiteira.

\subsection{A DINÂMICA DA PRODUÇÃO DE SUÍNOS NAS COOPERATIVAS E A PRESENÇA DAS INSTITUIÇÕES}

As duas cooperativas adotam o mesmo sistema produtivo. Primeiramente, são produzidos os leitões na UPL ou pelos produtores iniciadores. No período inicial que corresponde a quatro meses, o leitão é amamentado. Em seguida, ele é separado e fica em um setor chamado creche até atingir os $23 \mathrm{~kg}$. Posteriormente, é enviado aos terminadores que o encaminham à cooperativa central para abate e processamento. 
Como os leitões são produzidos de formas diferentes, pela UPL por meio da inseminação artificial e pelos produtores iniciadores de forma natural, há diferenças de qualidade. Desse modo, os gestores relatam que existe uma norma para estabelecer o recebimento pelos terminadores de cada origem, sendo intercalado UPL e iniciador. De acordo com os gestores, quando o suíno é produzido pela UPL, há assistência especializada, a garantia de que todas as vacinas serão administradas e a certeza de que o manejo será realizado de forma adequada. Esse controle não ocorre com os iniciadores, mesmo havendo orientação nesse sentido.

Segundo os gestores das cooperativas, existe o cuidado com a distribuição dos leitões. Porém, os produtores expõem que alguns preferem receber machos das UPLs, pois têm uma conversão alimentar melhor, ou seja, convertem mais ração em carne. Outros preferem receber de iniciador, pois a cooperativa paga um preço diferenciado para esses terminadores, devido à diferença na qualidade do leitão recebido. Isso significa que a norma interna descrita pelos gestores não funciona de forma plena.

Em relação ao regramento da instituição, o que se identificou, a partir das entrevistas, é que o que mais influencia o trabalho das cooperativas e dos produtores são as normas do Instituto Ambiental Paranaense (IAP). Os produtores relataram que as normas impostas pelo IAP são basicamente as seguintes: a pocilga deve ser instalada longe de nascentes, rios e mata ciliar; cuidado em relação aos dejetos; e preservação da reserva ambiental. Eles argumentaram ainda que existe uma demora considerável para conseguir todas as liberações, o que atrapalha o desenvolvimento da atividade. Segundo os produtores, falta um padrão nas cobranças feitas tanto pelas cooperativas quanto pelo IAP, que fazem exigências diferentes. Há também muitas questões burocráticas, o que influencia de forma negativa a atividade.

A partir das instituições tratadas por North (I99I), Williamson (I985), Zylbersztajn (I995), entre outros, nota-se que, no presente estudo, a presença delas é marcante. Podem-se analisar dois aspectos distintos. O primeiro refere-se às instituições externas, principalmente a Seab e o IAP, que atuam na fiscalização sanitária e na adequação às questões ambientais, respectivamente. Porém, a instituição que desenvolve maior influencia na relação é o IAP, devido às normas ambientais e à necessidade de liberação para o início da atividade. Já a Seab, foi pouco citada pelos produtores. Outro ângulo que pode ser analisado é a própria cooperativa que atua como uma instituição, ou seja, trata-se de microinstituição interna que desempenha o papel de determinar as regras tanto na atividade de suínos quanto na própria estrutura cooperada. 


\section{ATRIBUTOS DA TRANSAÇÃO E AS ESTRUTURAS DE GOVERNANÇA}

De acordo com Williamson (I985, I993), Zylbersztajn (I995) e Azevedo (2000), a racionalidade limitada identificada na transação gera custos ex post à transação para os produtores, pois, somente depois do início da atividade, estabelecem-se os acordos e as negociações com a cooperativa, que controlará a atividade dos produtores os acordos pós-contratuais. Diante disso, as contingências futuras são ajustadas por acordos estabelecidos depois de firmado o contrato de parceria, o que ratifica a flexibilidade dos contratos formais.

O oportunismo pode ocorrer, no caso do produtor, quando este não segue as regras imposta pela cooperativa e, por isso, não segue o comportamento preestabelecido pela cooperativa, ou usa de má-fé desviando a produção ou ração. No caso da cooperativa, a possibilidade do comportamento oportunista se apresentaria devido ao maior poder de decisão que ela concentra e pelo uso de informações privilegiadas, além do domínio do processo de mensuração. Como o produtor tem pouco conhecimento do mercado de suínos, como foi identificado pelas entrevistas, ele fica dependente das orientações da cooperativa. No entanto, apesar da dependência existente entre produtor e cooperativa, o que se percebe é que a relação de confiança não é plena entre eles.

Como apresenta Williamson (I985), a partir da combinação dos pressupostos comportamentais com os atributos da transação, é possível configurar as estruturas de governança. No que tange aos atributos, observaram-se os seguintes fatores: frequência quanto à continuidade da produção de suínos; incerteza em relação a aspectos como mercado, preços e clima; e especificidade dos ativos no que se refere às especificidades física, humana, locacional e dedicada.

A especificidade de lugar se relaciona a dois aspectos. O primeiro refere-se à proximidade entre a UPL e os produtores terminadores, pois um transporte muito longo pode acarretar problemas, influenciar na qualidade final e, consequentemente, resultar em falhas na mensuração. Além disso, a distância dos produtores terminadores em relação à cooperativa (nesse caso, a cooperativa central que recebe os suínos) também não pode ser muito longa. Para os gestores, essa distância é de no máximo I7o km. O segundo aspecto concerne à efetivação da atividade suinícola: o produtor deve cumprir rigorosamente as determinações do IAP sobre localização da pocilga, distância de margens de rios e reservas, e depósito de dejetos.

Ainda, notou-se a especificidade de ativos dedicados que se refere à instalação da pocilga, pois, segundo os produtores, caso não haja continuidade da atividade, existirá a perda do investimento, que é específico para a criação de suínos. 
O manejo, ou seja, a forma de tratar e cuidar dos animais, passa a ser também um ponto específico na produção, podendo ser caracterizado como uma especificidade humana. É a partir do manejo que os produtores conseguem melhores resultados de produção no que se refere aos índices de eficiência, os quais são específicos para a produção de suínos.

Também cabe observar que a especificidade física, nesse caso do leitão, pode trazer diferenciação no resultado final da produção de suínos. Isso ocorre porque parte da atividade corresponde à produção do leitão, e, se este atender às determinações de qualidade impostas pela cooperativa e pelo mercado, isso pode trazer melhorias para o produtor, pois ele terá menos custos devido a uma melhor mensuração.

Nesse caso, como a especificidade do produto é alta, é necessário o estabelecimento de contratos para garantir o cumprimento do que é estabelecido, tendo uma estrutura de governança mais adequada para minimizar os custos de transação. Na presença de baixa incerteza mas especificidade e frequência altas, faz-se necessária a contratação para prevenir perdas irrecuperáveis dos investimentos realizados. Esses aspectos justificam a configuração da estrutura de governança contratual.

É importante ressaltar que a forma de governança contratual é justificada também pelas condições de mensuração presentes na transação, pela possibilidade de controle da atividade por parte da cooperativa e pela necessidade de proteção contra comportamentos oportunistas e proteção de direitos de propriedade.

Apesar de a atividade ser direcionada por contratos formais, as relações no dia a dia são fortemente baseadas em acordos, o que, por sua vez, eleva os custos de transação para o produtor e para a cooperativa. Nesse caso, o produtor precisa constantemente negociar com a cooperativa para garantir seu direito de propriedade, e a cooperativa, por causa do excesso de flexibilidade, monitora e fiscaliza frequentemente a produção de suínos.

Isso pode ser justificado pela ausência de padronização dos produtores quanto ao manejo e à infraestrutura, e pela busca do controle da cooperativa sobre os produtores para manter a qualidade da produção devido a essas diferenças. No caso dos produtores, as pocilgas não têm o mesmo padrão em todas as propriedades, e, no caso do manejo, os produtores seguem a forma que eles julgam ser mais adequada em seu dia a dia. Alguns produtores, por exemplo, fazem a limpeza duas vezes ao dia, outros, porém, somente uma. No que se refere à cooperativa, as cobranças em relação à atividade também ocorrem de forma diferente para com os cooperados. Isso pode ser observado na questão do relacionamento entre eles, pois, se um produtor é mais amigável, acaba obtendo mais vantagens nas negociações. 
Percebe-se que a estratégia das cooperativas é o ganho de escala e escopo por meio da eficiência na produção, pois elas produzem suínos em larga escala e utilizam a cooperativa central para o abate de frangos e suínos, e como canal de distribuição. Para alcançar melhores resultados, as cooperativas cobram dos cooperados índices maiores de produção para que eles ganhem mais e, em contrapartida, para a cooperativa também ganhar mais.

De acordo com Hart e Moore (I988), os contratos de parceria, com as características de longo prazo, possibilitam a revisão de lacunas durante o tempo de validade. Assim, as partes estudadas ajustam os interesses por meio dos acordos informais para garantir a continuidade da transação e minimizar a apropriação da quase renda (Klein, Crawford, \& Alchian, I978).

Pelas informações apresentadas, a coordenação entre os agentes, a partir da contratação, faz-se necessária para garantir o direito das partes. O que confirma a proposta de Farina (I999), a qual considera a coordenação o resultado de uma construção dos agentes econômicos. A governança, neste estudo, é tratada, com base nas considerações de Williamson (1996), como uma estrutura institucional na qual as transações ocorrem; no caso desta pesquisa, por meio da atividade suinícola.

\section{ECONOMIA DOS CUSTOS DE MENSURAÇÃO E DIRETOS DE PROPRIEDADE}

Na produção de suínos, os gestores das cooperativas afirmaram que a mensuração apontada por Barzel (2005) se realiza em dois momentos: na propriedade dos produtores terminadores por meio dos técnicos de fomento e na entrega do suíno para a cooperativa central. No segundo caso, a mensuração ocorre somente pela cooperativa.

Observou-se que a mensuração na produção de suínos ocorre pelas duas partes, porém de formas e controles diferentes. Quando foram questionados sobre como mensuram, por exemplo, ganho de peso, peso final e problemas de sanidade com os suínos, os produtores afirmaram que a mensuração feita na propriedade, por meio da experiência e da observação diária dos suínos, é mais simples.

Já para a cooperativa, a mensuração ocorre em três momentos. No primeiro caso, a cooperativa tem o controle total dos leitões que nascem na UPL. Logo, a cooperativa controla todo o processo e faz a mensuração completa do leitão e o entrega ao terminador. Porém, no caso do produtor iniciador, esse controle por parte da cooperativa é parcial, pois o leitão é criado na propriedade e não na unidade da cooperativa. No segundo momento, a cooperativa faz a mensuração do leitão entregue na propriedade do terminador, por meio dos técnicos de fomento e de forma visual que é considerada mais simples. 
No terceiro momento, quando o suíno é descarregado na cooperativa central, a mensuração se torna mais complexa, pois utilizam-se ferramentas específicas para a mensuração na cooperativa central, porém estas não estão disponíveis para os produtores. Dessa forma, nessa última mensuração, observa-se a presença de um possível comportamento oportunista por parte da cooperativa, não deixando claro o procedimento para os produtores. Assim, quando ocorre o abate, é que a cooperativa verifica a pesagem, a gordura na carcaça, lesões e problemas de sanidade de forma mais específica. Após esse processo, é emitido para o produtor apenas um relatório dessa mensuração.

A mensuração por parte da cooperativa restringe o controle por parte dos produtores, uma vez que estes não acompanham o processo como um todo. $\mathrm{O}$ que se percebe é que a mensuração final limita o acesso do produtor às informações que podem assegurar-lhe o direito de propriedade, tratado por Barzel (I997). Ainda, notou-se que a cooperativa tem como identificar as diferenças de qualidade dos leitões e diferenciar a entrega para os produtores. Essa prática pode prejudicar o desempenho final do produtor terminador e não condiz com a norma interna de que a entrega do leitão deve ser intercalada entre UPL e iniciadores, bem como macho e fêmea.

Para justificar os contratos, devido às características já apresentadas, utiliza-se também a teoria dos custos de mensuração. Conforme visto, nessa teoria, quando existem ativos específicos, mas a mensuração não é difícil, o contrato preenche os requisitos para uma estrutura de governança adequada. Como salienta Barzel (2005), se os ativos são específicos, mas existe a possibilidade de mensuração pelas partes, o contrato supre as necessidades em face da integração vertical. Assim, os contratos de parceria caracterizam-se como estrutura de governança híbrida tratada por Williamson (I985) e ratificam as considerações de Barzel (2005), Zylbersztajn (2005) e Ménard (2004).

Como existe a má definição dos direitos de propriedade (por parte dos produtores), fica evidente a possibilidade de comportamento oportunista, o que ratifica a teoria dos custos de transação de Williamson (I985), bem como a teoria dos custos de mensuração de Barzel (I997, 2003, 2005). Isso ocorre também pela incompletude dos contratos que, devido a isso, dão margens a aspectos não contratados.

A existência de contratos incompletos, discutidos por Zylbersztajn (I995, 2009), Hart (1995) e Hart e Holmström (I987), influencia fortemente a garantia de direito de propriedade pelo direito econômico (Barzel, 2003), devido ao excesso de flexibilidade da transação. Como ocorrem muitos acordos entre as partes, isso pode servir como desestímulo à busca do direito legal, garantido pelo contrato formal. Assim, o direito econômico passa a ser mais efetivo para a cooperativa, amparado no direito legal, tendo em vista que o contrato incompleto, relacionado 
ao manejo, determina maior direito de intervenção da cooperativa. Além disso, a condição de produtor de fiel cooperado fortalece essa condição, pois quem tem maior poder de decisão na relação é a cooperativa e não o cooperado. Logo, o direito de propriedade passa a ser garantido e delimitado, tendendo a beneficiar mais a cooperativa do que o produtor cooperado.

Essa falta de delimitação dos direitos de propriedade para o produtor ocorre também pela mensuração feita pela cooperativa (Barzel, 2005). Isso acontece porque a mensuração se torna mais complexa, já que é realizada somente na cooperativa central. Dessa forma, a cooperativa usa de mecanismos de estímulo à produção, pagando pela eficiência para minimizar as diferenças e executar a medição. Entretanto, os resultados desse procedimento não são ratificados pelos produtores, os quais questionam a metodologia de remuneração utilizada.

Assim, o uso excessivo do direito econômico, devido à incompletude, e a alta flexibilidade presente nos contratos geram também para os produtores maiores custos de transação, embora satisfaça a cooperativa. Isso ocorre porque, como os contratos são muito mais desenvolvidos pelo lado de acordos do que pela parte formal, eles não têm o amparo da instituição para garantir o enforcement, tratado por Zylbersztajn (I995). Nesse caso, a garantia do cumprimento dos acordos é dada apenas pela cooperativa.

Pode-se perceber que as regras informais, existentes nas transações, são as que têm maior relevância quanto ao relacionamento dos produtores com as cooperativas. Nesse caso, infere-se que as regras formais são mais percebidas no início da atividade, sendo determinantes para formalização dos contatos de parceria, enquanto as regras informais se apresentam no decorrer do processo produtivo e se configuram no regramento efetivo para as transações.

As flexibilidades observadas nos contratos favorecem a cooperativa, o que pode indicar uma estratégia de coordenação dos produtores, já que isso permite um contato recorrente com eles, além de um controle implícito das atividades sem que um mecanismo de coerção aparente seja utilizado. Porém, o produtor de suínos deve cumprir o que é determinado pela cooperativa no que se refere aos aspectos informais e ser um bom e fiel cooperado.

\section{RELAÇÃO AGENTE E PRINCIPAL NA ATIVIDADE SUINÍCOLA}

A relação caracterizada neste estudo como agente e principal, conforme as considerações de Hart e Holmström (I987) e Bialoskorski (I998b), passa a ser determinada pelo principal - a cooperativa - e cumprida pelo agente - o produtor.

Notou-se, pelas entrevistas, que muitas vezes falta um tratamento padronizado para que os produtores possam ter, também, um desempenho final parecido. 
A cooperativa como principal incentiva o produtor como agente a desenvolver sua atividade, para que haja eficiência de produção e economia de escala. Nesse caso, como tratado por Holmström (I979), a cooperativa controla praticamente toda a atividade do produtor e, como incentivo, paga pela sua produção de acordo com seu desempenho. Esse incentivo serve para que o cooperado trabalhe de acordo com as determinações da cooperativa. Além disso, a cooperativa oferece cursos e treinamentos para os produtores e a comunidade, cumprindo o seu papel social na sociedade, o que, de certa forma, conquista os cooperados.

Um dos pontos estratégicos das cooperativas é a diversificação, pois aumenta o leque de produtores e eleva o valor agregado quando se industrializa uma grande quantidade de produtos, que concorrem em um mercado altamente competitivo, como no caso de embutidos, enlatados e carnes embaladas. As cooperativas investem também no segmento de supermercado que, de acordo com os gestores, é altamente rentável. Para as cooperativas, essa diversificação é necessária para que elas possam concorrer com outras organizações não cooperativas, que investem pesado em tecnologia e têm linhas de financiamento muito mais acessíveis.

A separação entre propriedade e controle tratada por Zylbersztajn (I999), Demsetz (I983) e Bialoskorski (200I) foi observada em dois casos diferentes:

- O cooperado, por prestar o serviço para a cooperativa, não mantém a propriedade nem o controle. Nesse caso, tais responsabilidades são da cooperativa.

- Quando a cooperativa não tem a relação contratual, como no caso dos grãos, ocorre a inversão. Assim, cabem ao cooperado a propriedade e o controle da atividade.

A cooperativa utiliza o contrato de suínos para minimizar a falta de controle sobre as demais atividades da cooperativa. Os produtores entrevistados não chegam a ver, a não separação de propriedade e controle, como um problema, como é tratado por esses autores.

Para os cooperados, o fato de o gestor da cooperativa ser um dos associados é bom e traz benefícios para a gestão. Todavia, os próprios gestores das cooperativas admitiram que, em alguns casos, os produtores cooperados não têm formação suficiente para gerenciar as atividades das cooperativas, o que acaba tendo ênfase à parte operacional e não à gerencial. Isso confirma o que é discutido por Zylbersztajn (I999), Demsetz (I983) e Bialoskorski (200I), no que se refere à separação entre propriedade e controle.

Em relação ao controle, como estão presentes tanto o contrato formal quanto os acordos, o mecanismo de punição também ocorre pelas duas vias. A punição 
formal referente à atividade de suínos ocorre por meio da execução do contrato quando os produtores não cumprem requisitos como eficiência de produção determinada pela cooperativa ou há desvio de ração e suínos.

As punições informais estão mais presentes na relação. A cooperativa utiliza o contrato de parceria dos suínos - um mecanismo que mantém a estrutura cooperada - para tornar os produtores sócios fiéis. O produtor que não entrega toda a produção para a cooperativa é penalizado de modo informal na produção de suínos. Pode-se inferir que os principais mecanismos de punição utilizados pelas cooperativas são relacionados à qualidade do suíno encaminhado ao produtor e ao tempo de vazio sanitário.

Para que o agente desempenhe suas funções de acordo com o esperado, a cooperativa utiliza, além da punição, mecanismos de incentivo e o monitoramento, o que ratifica o proposto na teoria da agência e nos contratos, como afirmam Holmström, (I979) e Milgrom e Roberts (I992). No caso do incentivo, a cooperativa paga o trabalho prestado pelo produtor com base em índices de eficiência de produção. Isso significa que, quando a conversão é melhor e o gasto com o trato dos suínos é menor, o produtor ganha mais ao final de cada lote. $\mathrm{O}$ monitoramento é desenvolvido pelos técnicos das cooperativas que fiscalizam o desenvolvimento da atividade pelos produtores. É a partir dessa fiscalização que ocorrem as punições e o controle para o pagamento da produção.

Por fim, ressalta-se que o cooperado no papel de agente, sendo também sócio da cooperativa que desempenha o papel de principal nesse momento da relação, assinala como importante o papel dos contratos na relação entre eles, pois isso garante a continuidade da transação e acaba por diminuir a incerteza, que se faz presente no mercado. Dessa forma, a estrutura de governança estabelecida pelo alinhamento dos atributos de transação e mensuração também sofre influência da própria estrutura cooperada, que é determinada pela relação mais estreita dos agentes.

Como resultado do estudo e com base nas categorias de análise apresentadas na metodologia, apresenta-se o Quadro I, que resume os principais pontos acerca de cada teoria estudada e suas inter-relações.

\section{QUADRO I}

\section{RESULTADO DA PESQUISA A PARTIR}

\section{DAS CATEGORIAS DE ANÁLISE}

- Regras formais: reservas legais, distância de nascentes, rios e matas ciliares, e descarte de dejetos.

- Regras informais: cooperativa, manejo, sanidade e infraestrutura.

(continua) 


\section{QUADRO I (CONCLUSÃO)}

\section{RESULTADO DA PESQUISA A PARTIR \\ DAS CATEGORIAS DE ANÁLISE}

\begin{tabular}{|c|c|}
\hline $\begin{array}{l}\text { Atributos da } \\
\text { transação }\end{array}$ & $\begin{array}{l}\text { - Possibilidade de comportamento oportunista pela cooperativa: pagamento } \\
\text { - Peito aos produtores. } \\
\text { ração e suínos. } \\
\text { - Racionalidade limitada pelo produtor: falta de conhecimento do mercado. } \\
\text { - Racionalidade limitada pela cooperativa: impossibilidade de conhecer todas } \\
\text { as contingências para redigir o contrato. } \\
\text { - Frequência: no caso dos lotes, a frequência é alta, pois o contrato é por } \\
\text { tempo indeterminado. } \\
\text { - Incerteza: aspecto relacionado ao preço pago pelo mercado para a } \\
\text { cooperativa (o que influencia o pagamento aos produtores), às leis } \\
\text { ambientais e ao clima. }\end{array}$ \\
\hline Mensuração & $\begin{array}{l}\text { - Mensuração: mais simples quando feita na propriedade pelo produtor e } \\
\text { pela cooperativa: peso, sanidade e limpeza. } \\
\text { - Mensuração mais complexa feita após o abate e somente pela cooperativa: } \\
\text { peso final e problemas de sanidade, mortes durante o trajeto, entre outros, } \\
\text { - que gera o cálculo para pagamento. } \\
\text { - Direito legal: pagamento pelo lote entregue à cooperativa. } \\
\text { lucro ao produtor para compensar um lote anterior. } \\
\text { - Direito de propriedade: é afetado pela existência de acordo, devido ao } \\
\text { direito econômico. }\end{array}$ \\
\hline $\begin{array}{l}\text { Estruturas de } \\
\text { governança }\end{array}$ & $\begin{array}{l}\text { - Hibrida: contratual e por tempo indeterminado (contrato de parceria). } \\
\text { - Formal: contratos. } \\
\text { - Informal: acordo entre as partes e excesso de flexibilidade. }\end{array}$ \\
\hline $\begin{array}{l}\text { Agente e } \\
\text { principal }\end{array}$ & $\begin{array}{l}\text { - Interesse da cooperativa: controle da produção total do produtor rural, } \\
\text { - Inaior produtividade e fidelidade do cooperado. } \\
\text { complemento de renda e distribuição das sobras. } \\
\text { - Incentivo: pagamento e aumento de renda. } \\
\text { - Monitoramento: controle e fiscalização. } \\
\text { - Punição formal: por meio do contrato. } \\
\text { - Punição informal: por meio de relações informais, acordos e na própria } \\
\text { produção de suínos. }\end{array}$ \\
\hline
\end{tabular}

Fonte: Elaborado pelos autores. 
Deve-se ressaltar que as cooperativas coordenam atividades com os produtores rurais e alinham as especificidades e dimensões mensuráveis presentes nas transações por meio das relações contratuais, dada a interdependência entre as partes envolvidas na transação. A cooperativa, responsável pelo regramento da atividade, trabalha como uma microinstituição interna, relacionada à atividade $\mathrm{e}$ à estrutura da organização cooperativa.

Destaca-se que os problemas relacionados, principalmente, à mensuração não são sanados pelo estabelecimento dos contratos formais, uma vez que estes não abarcam todas as contingências ex post à contratação, o que os caracteriza como contratos incompletos. Dessa forma, abrem espaço para negociações posteriores e margens não contratadas.

\section{CONSIDERAÇÕES FINAIS}

O objetivo do presente trabalho foi compreender como os atributos de transação e a mensuração influenciam as relações contratuais entre produtores e processadores em estruturas cooperadas suinícolas localizadas na região oeste do Paraná. Observou-se que a dinâmica da produção de suínos em ambas as cooperativas ocorre de forma parecida com UPL e terminadores para a produção de leitão, com o objetivo de conseguir ganhos de escala e eficiência na produção. Isso é possível pelo envolvimento de pequenos produtores que precisam complementar a renda com a diversificação da produção, o que garante para a cooperativa maior controle e melhor coordenação.

Em relação aos atributos da transação e pressupostos comportamentais, identificaram-se racionalidade limitada, oportunismo, incerteza, frequência e especificidade de ativos. Quanto à mensuração, observou-se, na terminação, que é considerada fácil de ser feita, tanto pelos cooperados como pelas cooperativas, e que ocorre no dia a dia e de modo visual.

Porém, a mensuração final, que ocorre no abate dos suínos, é feita apenas pela cooperativa central, ligada às cooperativas. Essa cooperativa central efetua o cálculo final de ganho de peso determinando os descontos para o pagamento aos produtores. Nesse aspecto, foi possível observar a existência de assimetria de informação, bem como de informação incompleta, o que ocorre principalmente por parte dos produtores e prejudica a delimitação de seus direitos de propriedade. Em relação aos papéis desempenhados pelas cooperativas e pelos cooperados, os estudos permitiram identificar que existem tratamentos diferenciados por parte da cooperativa em relação aos produtores, o que pode influenciar na mensuração do desempenho final do produto, possibilitando distorções nas garantias de direitos de propriedade e, como consequência, custos de agência. 
O contrato formal é visto pelos agentes entrevistados como garantia para o cumprimento das obrigações, pois os produtores fazem um investimento específico de valor considerável (criação de quase renda). Se a cooperativa não cumprir a parte que lhe cabe, não se poderá utilizar esse investimento para outro fim. Entende-se que o contrato de parceria para a atividade suinícola apresenta uma dupla função: serve como mecanismo de manutenção da cooperativa para com os produtores e é utilizado pela cooperativa como ferramenta para a fidelização dos cooperados em outras atividades, como grãos e leite. Essa fidelização se refere ao fato de que o cooperado, por ter um contrato de parceria dos suínos, mesmo que de modo informal, se vê pressionado a entregar o resultado das outras atividades de produção à cooperativa para manutenção e normalidade da atividade suinícola.

Essas considerações indicam que as relações são permeadas por instabilidades que podem afetar a eficiência dos mecanismos de governanças identificados. Essa perspectiva inicial indica a necessária continuidade de estudos tanto para o Sistema Agroindustrial (SAG) suinícola quanto para relações cooperadas. Além disso, estudos orientados para outras atividades cooperadas, formas de relação e de organização cooperativa, sob esses aportes teóricos, devem contribuir para um melhor entendimento desse fenômeno.

\section{INFLUENCES OF TRANSACTION AND MEASUREMENT COSTS IN THE RELATIONSHIPS INVOLVING MEMBERS AND COOPERATIVES OF SWINE AGRICULTURE SYSTEM}

\section{ABSTRACT}

This article seeks to discuss the relationship between the cooperative and cooperative transactions specifically swine, which involves attributes of the transaction and measurement dimensions. Therefore, the aim of this article was to understand how the attributes of the transaction, proposed by Williamson (1985), and the measurement, proposed by Barzel (2005), may influence the contractual relations between producers and processors in swine cooperative structures, located in the west of Paraná. In order to attend this goal was performed a descriptive qualitative research in two cooperatives in western Paraná. Data collection was carried out by obtaining secondary data from the Organization of Brazilian Cooperatives, Research Institutes, Department of Agriculture and agencies related 
to the swine activity. In relation to primary data, data was collected through a semi-structured interview with cooperatives and producers. As a result it was found that the governance structure used by cooperatives was characterized as hybrid, which even with the presence of highly specialized asset is justified by the possibility of measurement. The contracts between the parties are formal and informal. On the other hand, the presence of agreed issues, which involve some degree of accuracy and measurement, may generate loss of property rights, primarily for producers. On the other hand, the presence of agreed issues, which involve some degree of accuracy and measurement, may generate loss of property rights, primarily for producers. It was also identified that contracts play a dual role in the relationship between the parties: I. creating a balance in the relationship and reducing the possibility of opportunistic behavior, given the specific investment made and the need to obtain standardized product and process; 2. using also as a mean in order to keep the swine cooperated producer as a faithful partner in the cooperative, acting as a form of support between the agent and the principal.

\section{KEYWORDS}

Transaction costs. Cost measurement. Contracts. Cooperatives. Swine chain.

\section{ATRIBUTOS DE LA TRANSACCIÓN Y MEDICIÓN Y SU INFLUENCIA EN LAS RELACIONES ENT'RE COOPERADOS Y COOPERATIVAS EN LOS SISTEMAS AGROINDUSTRIALES DE LA CADENA PORCINA}

\section{RESUMEN}

En este artículo se aborda la temática de las relaciones entre cooperados y cooperativas, considerando las transacciones de la industria porcina, de dimensiones considerables. Por lo tanto, el objetivo de este artículo fue comprender cómo los atributos comerciales y la mensuración pueden influenciar en las relaciones contractuales entre productores y procesadores de las estructuras cooperadas porcinas localizadas en la zona oeste del Paraná. Del artículo tiene el soporte de las teorías de costos de transacción de Williamson (I985) y de costos de medición de Barzel (2005). Para alcanzar el objetivo propuesto fue realizada una encuesta cualitativa de carácter descriptivo en dos cooperativas en el oeste paranaense. La 
obtención de la información fue desarrollada a través de la obtención de datos secundarios de la Organización Brasileña de Cooperativas, Institutos de Investigación, Secretaría de Agricultura y órganos relacionados a la actividad porcina. En lo que se refiere a los datos primarios, éstos fueron obtenidos por medio de una entrevista medio estructurada con las cooperativas y productores. Como resultado se identificó que la estructura de orientación aplicada por las cooperativas se caracteriza como híbrida, la cual aún con la presencia de alta especialidad de activos se justifica por la posibilidad de medición. Los contratos entre las partes son formales. En relación al contrato formal, este tiene relevancia para las partes, en el sentido que brinda garantía y continuidad de la actividad. Por otro lado, la presencia de aspectos acordados, que envuelven cierto grado de exactitud y medición, puede generar pérdida del derecho de propiedad, primordialmente para los productores. Se identificó también que los contratos pasan a desempeñar un doble papel en la relación entre las partes: I. generando equilibrio en la relación y reduciendo la posibilidad de actitud oportunista, dados la inversión específica realizada y necesidad de obtención del estándar del producto y del proceso; 2. utilizando, todavía, como un mecanismo para mantener al cooperado productor porcino como socio fiel en la cooperativa, actuando como un forma de manutención en la relación agente y principal.

\section{PALABRAS CLAVE}

Costos de transacción. Costos de medición. Contratos. Cooperativas. Cadena porcina.

\section{REFERÊNCIAS}

Adam, P. (200I). Sobre o desenho do estado: uma perspectiva agente e principal. In C. B. Pereira \& P. K. Spink. Reforma do estado e administração pública gerencial (4a ed.). Rio de Janeiro: FGV.

Alchian, A. A. (1965). Some economics of property rights [Reimpresso em Economic forces at work. Indianapolis: Liberty Fund, I977]. II Politico, 30, 816-829.

Alchian, A. A., \& Demsetz, H. (1972). Production, information costs, and economic organization. The American Economic Review, 62(5), 777-795.

Anuário da pecuária brasileira - Anualpec (20II). São Paulo: Instituto FNP.

Azevedo, P. F. de. (2000). Nova Economia Institucional: referencial geral e aplicações para a agricultura. Agricultura, 47(I), 33-52.

Barzel, Y. (I997). Economic analysis of property rights. Cambridge: Cambridge University Press. Barzel, Y. (2003). Property rights in the firm. In T. L. Anderson \& F. S. Mcchesney. (Eds). Property rights: cooperation, conflict and law (pp. 43-57). New Jersey: Princeton University Press. 
Barzel, Y. (2005). Organizational forms and measurement costs. Journal of Institutional and Theoretical Economics, 161, 357-373.

Bauer, M. W., \& Gaskell, G. (2002). Pesquisa qualitativa com texto, imagem e som: um manual prático (3a ed.). Petrópolis: Vozes.

Berle, A., \& Means, G. (I932). The modern corporation and private property. New York: Macmillan.

Bialoskorski, S., Neto (I998a). Ensaios em cooperativismo. (Série didática, I2I). Piracicaba: Esalq/USP.

Bialoskorski, S., Neto (I998b). Cooperativas: estrutura, crescimento e estrutura de capital. Tese de doutorado, Universidade de São Paulo, Piracicaba, SP, Brasil.

Bialoskorski, S., Neto (200I). Governança e perspectivas do cooperativismo. In R. Panzutti (Org.). Coleção Estudo e Pesquisa ${ }^{\circ}$ 3. São Paulo: Ocesp, Sescoop-SP.

Bialoskorski, S., Neto (2007). Um ensaio sobre desempenho econômico e participação em cooperativas agropecuárias. Revista de Economia e Sociologia Rural, 45, II9-138.

Cheung, S. N. S. (I969). The contractual nature firm. Journal of Law and Economics, 26, I-2I.

Coase, R. H. (I937). The nature of the firm. Economica, 4(I6), 385-405.

Creswell, J. W. (2007). Projeto de pesquisa: método qualitativo, quantitativo e misto (2a ed.). Porto Alegre: Bookman.

Demsetz, H. (1983). The structure of ownership and the theory of the firm. The Journal of Law \& Economics, 26, 375-390.

Farina, E. M. M. Q. (I999, dezembro). Competitividade e coordenação de sistemas agroindustriais: um ensaio conceitual. Revista Gestão e Produção, 6(3), I47-I6I.

Farina, E. M. M. Q., Azevedo, P. F. de, \& Saes, M. S. M. (I997). Competitividade: mercado, estado e organizações. São Paulo: Singular.

Hart, O. (I995). Firms, contracts and financial structure. Oxford: Clarendon Press.

Hart, O., \& Holmström, B. (I987). The theory of contracts. In T. F. Bewley. Advances in economic theory. Fifth World Congress. Cambridge: Cambridge University Press.

Hart, O., \& Moore, J. (I988). Incomplete contracts and renegotiation. Econometrica Society, $56(4), 755-785$.

Holmström, B. (I979). Moral hazard and observability. The Bell Journal of Economics, 10(I), 74-9I. Jacobides, M. G., \& Winter, S. G. (2005). The co-evolution of capabilities and transaction costs: explaining the institutional structure of production. Strategic Management Journal, 26, 395-4I3.

Klein, B., Crawford, R. G., \& Alchian, A. A. (I978). Vertical integration, appropriable rents, and the competitive contracting process. Journal of Law and Economics, 21(2), 297-326.

Liberatore, M. J., \& Luo, W. (2010). Coordination in consultant-assisted IS Projects: an agency theory perspective. IEEE Transactions on Engineering Management, 57(2).

Ludke, M., \& André, M. E. D. A. (I986). Pesquisa em educação: abordagens qualitativas. São Paulo: EPU. Ménard, C. (2002). The economics of hybrid organizations. Journal of Institutional and Theoretical Economics, $160(3)$, 345-376.

Merriam, S. B. (1998). Qualitative research and case study: applications in education. San Francisco: Jossey Bass.

Milgrom, P., \& Roberts, J. (I992). Economics, organization \& management. New Jersey: Prentice Hall.

North, D. (I99I). Institutions. The Journal of Economic Perspectives, 5(I), 97-II2.

Organização das Cooperativas Brasileiras (2013). Relatório OCB: cooperativas constroem um mundo melhor. Brasília: OCB. Recuperado em abril, 2013 de http://www.ocb.org.br. 
Organização das Cooperativas do Estado do Paraná (20I3). Relatório OCB 2OI2: cooperativas constroem um mundo melhor. Recuperado em 20 maio, 2013, de www.ocepar.org.br/ocepar.

Saes, M. S. M. (2009). Estratégias de diferenciação e apropriação da quase-renda na agricultura: a produção de pequena escala. São Paulo: Annablume, Fapesp.

Secretaria de Estado da Agricultura e do Abastecimento (2013). Recuperado em 20 maio, 20I3, de www.seab.pr.gov.br/modules/conteudo/conteudo.php?conteudo=I37.

Sexton, R. J. (1986). Co-operatives and the Forces Shaping Agricultural Marketing. American Journal of Agricultural Economics, 68(5), II67-II72.

Shapiro, S. P. (2005). Agency theory. Annual Review of Sociology, 31, 263-284.

Williamson, O. E. (I985). The economic institutions of capitalism: firms, markets, relational contracting. New York: Free Press.

Williamson, O. E. (I993). Transaction cost economics and organization theory. Journal of Industrial and Corporate Change, 2, 107-156.

Williamson, O. E. (1996). The mechanisms of governance. New York: Oxford University Press.

Williamson, O. E. (2000). The New Institutional Economics: taking stock, looking ahead. Journal of Economic Literature, 38(3), 595-613.

Zylbersztajn, D. (1994, julho/setembro). Organização de cooperativas: desafios e tendências. RAUSP - Revista de Administração da Universidade de São Paulo, 29(3), 23-32.

Zylbersztajn, D. (I995). Estruturas de governança e coordenação do agribusiness: uma aplicação da nova economia das instituições. Tese de livre-docência, Universidade de São Paulo, São Paulo, SP, Brasil. Zylbersztajn, D. (I999). Empresas cooperativas: reestruturação e sobrevivência. Faculdade de Economia, Administração e Contabilidade e Fundação Instituto de Administração. São Paulo. Relatório de pesquisa CNPq.

Zylbersztajn, D. (2005a). Measurement costs and governance: bridging perspectives of transaction cost economics. In D. Zylbersztajn. International Society for the New Institutional Economics Isnie. Barcelona, Spain.

Zylbersztajn, D. (2005b). Economia das organizações. In D. Zylbersztajn \& M. F. Neves (Orgs.). Economia e gestão dos negócios agroalimentares: indústria de alimentos, indústria de insumos, produção agropecuária, distribuição. São Paulo: Pioneira Thomson Learning.

Zylbersztajn, D. (2009). Papel dos contratos na coordenação agro-industrial: um olhar além dos mercados. In J. P. de Souza \& I. N. do Prado. Cadeias produtivas: estudos sobre competitividade e coordenação (2a ed.). Maringá: Eduem. 